\title{
Evaluating the implementation fidelity of a multi-component intervention for oral health promotion in preschool children
}

\author{
S. Van den Branden ${ }^{1}$, S. Van den Broucke ${ }^{2}$, R. Leroy $^{3}$, D. Declerck ${ }^{3}$, K. \\ Hoppenbrouwers ${ }^{1}$
}

\author{
${ }^{1}$ Youth Health Care, Katholieke Universiteit Leuven, 3000 Leuven, Belgium \\ ${ }^{2}$ Psychological Sciences Research Institute, Université Catholique de Louvain, 1348 \\ Louvain-la-Neuve, Belgium and Health Psychology, KU Leuven, 3000 Leuven, Belgium \\ ${ }^{3}$ Department of Oral Health Sciences, Katholieke Universiteit Leuven, 3000 Leuven, Belgium \\ E-mail addresses: \\ sigrid.vandenbranden@med.kuleuven.be \\ stephan.vandenbroucke@psy.kuleuven.be \\ roos.leroy@med.kuleuven.be, roos.leroy@kce.fgov.be \\ dominique.declerck@med.kuleuven.be \\ karel.hoppenbrouwers@med.kuleuven.be
}

Correspondence:

Sigrid Van den Branden

Youth Health Care

Katholieke Universiteit Leuven

Kapucijnenvoer 35, Block D PO 7001

B - 3000 Leuven, Belgium

Email: sigrid.vandenbranden@med.kuleuven.be 
Abstract

This study evaluates the process of implementation of a longitudinal intervention program to promote oral health in preschool children in Flanders, Belgium. As the program was implemented in an existing preventive health care organization, the study also evaluates this setting as the context for implementation. Qualitative and quantitative methods were used to evaluate implementation fidelity, based on Carroll's theoretical framework of implementation fidelity (Carroll et al., 2007). Questionnaire data from participants and health workers were analyzed and document analyses were performed to compare registrations of the actions with the planning manual. Results were mixed. Whereas more than $88 \%$ of all parents attended all home visits, only 57\% received at least 9 of the 11 planned consultations. Fifty-two percent of the families received all supporting materials and on average $73 \%$ of all attending families received all information at a contact as described in the manual. Moderating factors such as the adequate use of facilitators and high participant responsiveness had a positive impact on implementation fidelity, whereas the quality of delivery differed to a great extent between the nurses who were involved during the entire intervention period and those who gave only a few sessions. Implementing an intervention in an existing well-baby program has many advantages, although lack of time presents a challenge to implementation fidelity. The results of this process evaluation allow a better understanding of the contribution of implementation fidelity to the effectiveness of health promotion programs.

Keywords: implementation fidelity, oral health promotion, preschool children, multicomponent intervention 


\section{Introduction}

Dental caries remains a considerable health problem in young children. According to data from the US, the prevalence of caries in 2 to 5 year old children has increased from $24 \%$ in 1988-1994 to 28\% in 1999-2004 (Tinanoff \& Reisine, 2009). In Flanders (Northern part of Belgium), caries was detected in almost one out of three five-year olds (Declerck et al., 2008). Caries experience is associated with many physical and psychological problems, affecting overall growth, development and quality of life of the child and his or her family (Locker, 2004; Plutzer \& Spencer, 2008; Sheiham, 2006). The estimated public health cost of dental caries in Flanders amounted to $€ 185$ million in 2010, excluding the costs for sick leave or hospitalization related to treatment under general anesthesia (Source: The National Institute for Health and Disability Insurance (NIHDI), 2010).

The prevalence of caries is to a large extent determined by behavioral factors, such as the frequent consumption of sugary snacks and drinks, insufficient oral hygiene and delaying preventive visits to the dentist (Declerck et al., 2008; Harris, Nicoll, Adair, \& Pine, 2004; Scottish Intercollegiate Guidelines Network (SIGN), 2005). In preschool children the development of these habits is mediated by parent behaviors, particularly of the primary caretaker (Mohebbi, Virtanen, Murtomaa, Vahid-Golpayegani, \& Vehkalahti, 2008). Therefore several interventions have been developed to reduce dental decay or to improve oral healthrelated behaviors by educational programs targeted towards parents (Davies, Duxbury, Boothman, Davies, \& Blinkhorn, 2005; Feldens, Vitolo, \& Drachler, 2007; Kowash, Pinfield, Smith, \& Curzon, 2000). In Flanders, the community-based oral health promotion intervention program "Smile for Life” was developed, targeting preschool children and their parents. The program was embedded in the framework of the "well-baby clinics", where preventive health care and educational guidance are offered free of charge by trained professionals to children from birth until the age of three and to their parents. 
Although the "Smile for Life" program was based on the Theory of Planned Behavior (TPB; Ajzen, 1991) and developed and implemented with the use of the Precede-Proceed model (Green \& Kreuter, 1999), an evaluation using a pre-post test design with a control group revealed only limited effects at the level of oral health and oral health-related behavior after three and five years. Two hypotheses were advanced to explain these limited effects: either the intervention was not effective, and/or implementation was poor or incorrect. The latter can be explored through an in-depth process analysis, including an evaluation of the implementation fidelity. Such an evaluation comprises a comparison of the actual delivery of the program with the intended program as formulated in the planning manual.

Several theoretical models have been proposed to consider the implementation fidelity of interventions. The model developed by Carroll et al. (2007) is currently the most complete framework for implementation fidelity, and has been used extensively for health interventions. The principal component in this framework is adherence, which refers to the participants' receipt of the active intervention ingredients with the planned dosage. Adherence can be operationally defined with four subcategories, namely the coverage, content, frequency and duration of the intervention. The term coverage refers to the proportion of parents who were exposed to the intervention as intended. Three other factors used to evaluate how much of the intervention's prescribed content has been delivered (content), how frequently (frequency) and for how long (duration).

Level of implementation fidelity is moderated by four interrelated variables. The first moderator is intervention complexity: the more complex an intervention, the harder it is to duly implement it. There is evidence that a higher level of fidelity can be reached when the description of the intervention is more specific and detailed. The second moderator is the availability of facilitation strategies that help to optimize and standardize the fidelity of the implementation, such as a manual, training and feedback. The third moderator is termed the 
quality of delivery, which is defined as "the manner in which a program implementer delivers a program”. The fourth moderator is participant responsiveness, positing that when the participants are enthusiastic, higher implementation fidelity will be achieved. Hasson (2010) has suggested two additional moderators, namely recruitment and context. The former involves the procedure for selecting and recruiting participants, the reasons for non-participation, and the presence or absence of specific subgroups among the participants, which can also impact on participation. Context refers to the organizational structure and the culture in which the intervention takes place. A theoretical framework showing the relationship between the intervention, adherence, outcomes and moderators is presented in Figure 1. Ideally, a process evaluation should include all the elements of this framework. The aim of the present study is to evaluate implementation fidelity in the "Smile for Life" study, using this conceptual framework. To our knowledge, this is the first study to systematically investigate the implementation fidelity of an oral health promotion program.

\section{Method}

\section{The "Smile for Life" intervention study}

All children born between October 2003 and July 2004 in two geographical regions in Flanders were invited to participate in this study. One region - involving 1284 newborns - served as the intervention region, and another - involving 1171 newborns - as the control region. Criteria for the selection of the control region were: (1) similar socio-economic characteristics, (2) a similar attendance rate at the well-baby clinics, and (3) at least $100 \mathrm{~km}$ away from the intervention region to minimize any potential interventional "contamination" of the control region. 
Parents were informed about the project shortly after their child's birth by a nurse of the well-baby clinic and parental informed consent was obtained. As the preventive health services are free of charge and the coverage of the target group was high (up to 97\% receives at least one home visit), parents from all social backgrounds were reached. Reasons for exclusion were provided in earlier reports (Leroy, Bogaerts, Martens, \& Declerck, 2011; Van den Branden, Van den Broucke, Leroy, Declerck, \& Hoppenbrouwers, 2012). In total, 1080 (84\%) and 1057 (90\%) children in the intervention and control groups were included in the study and followed until the age of five.

A specific intervention program to promote oral health was developed and added to the standard program of preventive health care at the well-baby clinics. The standard program consisted of three home visits by a nurse, and 11 consultations by a physician and nurse between the child's birth and age three. It included regular assessments of the health, growth and development of the child and health education for the parents. Oral health-related education in the standard program was limited to information about oral hygiene at six months and dental attendance at 24 months. The control group received this standard program.

For parents in the intervention group, additional oral health-related education was provided through the nurses on 14 topics, like breast feeding, pacifier use, parental oral hygiene, water consumption, and brushing behavior. This oral health information was addressed once or more during the 14 scheduled contact moments (i.e., home visits and consultations), together representing a total of 55 information items. The average number of items scheduled at a given contact was four. All nurses working in the intervention region received specific training on oral health and several training and feedback sessions were organized during the intervention period to keep their knowledge up to date and to discuss problems encountered during the intervention.

As previous studies indicated that oral health education alone was only effective in increasing knowledge (Strippel, 2010; Vachirarojpisan, Shinada, \& Kawaguchi, 2005), the 
parents also received supplementary educational materials (i.e., child health booklet, toothbrush, toothpaste sample, cup and placemat). All intervention components are presented in Table 1. Furthermore, all health care professionals practicing in the intervention region were informed about the project and posters were provided to inform their patients. The program was based on the concepts of behavioral change described in the TPB (Ajzen, 1991). In addition to the TPBdeterminants, factors related to memory and attention processes were also used to evoke a behavior change. For every determinant of behavior, behavioral change methods were used that were recently judged to be effective in changing the behavior based on expert consensus (Michie, Johnston, Francis, Hardeman, \& Eccles, 2008). The determinants and applied techniques are presented in Table 2.

To evaluate the effect of the study, reported oral health-related behaviors and psychological determinants based on the TPB were assessed with pretested and validated questionnaires (Van den Branden, Van den Broucke, Leroy, Declerck, \& Hoppenbrouwers, 2013) shortly after birth (2003-2004) and when the child had reached the age of three (2007) and five (2009). The TPB determinants were significant predictors of intentions and behaviours. Oral health examinations were performed by trained dentist-examiners in the kindergartens at age three and five to investigate clinical signs of visible caries experience. A detailed description of these procedures was provided earlier (Leroy et al., 2011). The "Smile for Life" study protocol received ethical approval from the Medical Ethics Committee at the Katholieke Universiteit Leuven, Belgium.

\section{Measures of implementation fidelity}

All core components of the model of Carroll (Carroll et al., 2007) were measured to evaluate implementation fidelity among the participants of the intervention group. 
Adherence. Adherence was measured with four components: coverage, content, frequency and duration. To evaluate the coverage, the proportion of parents who received the home visits and/or attended the consultations was calculated. Having attended all three home visits and nine out of eleven consultations was considered a cut-off for adequate participation. To evaluate whether the information and materials were delivered with the content and frequency as planned, the number of topics and materials received by the parents were calculated. The cut-off was set on 41, which equals percentile 75 of the total amount of 55 topics. For every contact moment, the intervention dose was calculated: the number of topics and materials delivered was divided by the maximum number of intervention components planned. Duration was measured by calculating the time spent on the intervention. The nurses were asked to make an estimation of the time they spent on average on the oral health-related education. A cut-off for an adequate duration could not be a priori determined, as the intervention was included in the standard program and was tailored to the individual needs of each family.

Moderating factors. Data were collected for three moderating factors mentioned in the model: the use of the facilitating factors, the quality of delivery and the participant responsiveness. It was not feasible to collect data regarding the remaining moderators of the model, but these will be addressed in the discussion section.

To evaluate whether implementation fidelity was enhanced through the use of the facilitators, it was investigated (1) whether the training was sufficient in terms of content, extensiveness and practical applicability and (2) whether the majority of nurses used the manual and child health booklet. The quality of delivery was evaluated by investigating the differences in the way the nurses implemented the intervention, reflecting the effect of training. To evaluate participant responsiveness, both nurses and parents were questioned. The nurses were asked (1) 
if parents showed interest in the oral health information provided, (2) if they were enthusiastic about the materials and (3) if they kept record of the tooth emergence sequence of the children. Next, it was investigated whether (1) parents thought they learned something from the project and whether (2) their attitudes changed as a result of the program. We did not find any cut-off scores for these factors in the literature. Therefore the evaluation of the proportions was done qualitatively in comparison with the planning manual.

The following data sources were used to evaluate the moderating factors. First, the participating nurses and physicians completed a questionnaire to evaluate the implementation process in 2004 (both nurses and physicians) and 2005 (nurses). The questionnaires contained 35 items for the nurses and 13 for the physicians, addressing beliefs about the adequacy of the training, the meaning and feasibility of the intervention, feelings related to implementation, participant responsiveness, use of materials and timing. For the majority of questions, participants were asked to rate their answers on a 5-point scale ranging from 'not at all' to 'strongly agree'. Open-ended questions were inserted for detailed clarifications. After the analysis of the registration and questionnaire data, a focus group interview was held with the nurses. Ten questions were developed by the researchers, to clarify some ambiguities that had arisen from the analyses and to confirm the results derived from the other data sources. The focus group discussion was moderated by one researcher and assisted by a second researcher. The conversation was audio-taped; a verbatim transcript of the entire focus group discussion was produced and compared with the handwritten notes taken by the researchers to fill in the gaps. Concluding remarks were formulated and discussed to reach consensus between both researchers and to avoid subjective interpretations. The conclusions were summarized in a written document.

Secondly, at the end of the implementation in 2007, the parents' experiences with the project were assessed via a questionnaire. Two questions were applied to investigate whether they had learned something from the project and whether they noticed a change of their attitudes 
towards oral health. Answers were given on a five-point Likert scale ranging from 'nothing at all' to 'a lot'.

\section{Data Analysis}

To evaluate the implementation fidelity of the "Smile for Life" project, quantitative and qualitative methods were used in a complementary manner (Malterud, 2001). In order to evaluate the adherence and moderating factors of implementation fidelity, the data records registered by the nurses and of the questionnaire data were analyzed using SPSS Statistics 17. After data cleaning, descriptive statistics and cross-tabs were calculated. Systematic document analyses were executed to compare the planning manual with the nurses' registrations during implementation. To facilitate comparisons, all planned actions were extracted from the manual and listed in a data file. The comparisons were performed by one researcher, under supervision of four other researchers.

\section{Results}

\section{Adherence}

Coverage. All families included in the intervention except 5 received at least one home visit, and 1039 (96\%) families were present on at least one consultation. A total of 954 families (88\%) received all three home visits. The number of children who received at least 9 of the 11 planned consultations was 618 (57\%). On average, at each contact moment $78 \%$ of parents were present (Table 3). A lower attendance rate was observed for consultation 1 (32\%) and to a lesser extent for consultations 10 (62\%) and 11 (51\%). The reasons for these “dips” in attendance were given during the focus discussion, where the nurses explained that in case of time shortage in the 
well-baby clinics organization, the first and/or last consultations were not offered to the parents as no vaccinations were scheduled at these contact moments.

Content and frequency. On average, $64 \%$ of the intervention (topics and materials) was delivered to the parents (Table 3). The number of informational items received by the parents ranged between 2 and 55, with a mean of $34.8(S D=12.1)$. Only $10 \%$ of the families received less than 14 items ( $25^{\text {th }}$ percentile) and $41 \%$ received more than 41 ( $75^{\text {th }}$ percentile); the median score was 37. For 14 children (1\% of the intervention group) there was no trace of any oral health information provided. As revealed from the focus discussion, the reasons why not all parents received the scheduled information was either that the parent was absent and therefore could not be offered the information (this was the case for on average $22 \%$ of parents) or that there were other (e.g. medical, educational) problems that needed to be discussed within the short time available, leaving not enough time for oral health education. The latter was the case for on average $14 \%$ of the parents. Overall, however, $73 \%$ of the parents present at a given contact received the oral health information items as planned. The only exceptions were consultations 10 and 11 , where many attending parents did not receive all the information, even after excluding the high absence rates. An analysis of the records showed that the topic for which education was least often provided was the advice to visit the dentist.

With regard to the distribution of the materials, the child health booklet was distributed as planned to all participants at the first home visit. When the first tooth emerged around the age of six months, $73 \%$ of the children in both regions received a toothbrush, a sample of toothpaste and a cup. The placemat was offered to $81 \%$ of the children and the second toothbrush and toothpaste were given to $83 \%$ of the children.

In all, $52 \%$ of the children received all three educational materials, $34 \%$ only two, and $15 \%$ only one. For 131 children (12\% of the intervention group) there had been no registration of these items. A discussion about this inconsistency during the group conversation with the nurses 
revealed that these children had probably received the materials, but that this had not been registered in the computerized child record due to high work load.

Duration. When asked how much time was spent on average on oral health education, $53 \%$ of the nurses reported to have spent more than 10 minutes during the first home visit to inform the parents about the project, ask their consent, distribute the questionnaire and provide the first scheduled oral health topics. The remaining $47 \%$ of the nurses spent between 5 and 10 minutes. During the following home visits, all nurses spent less than 10 minutes to cover the scheduled oral health topics, but on average $80 \%$ of them used more than five minutes. During the consultations, approximately $69 \%$ of the nurses spent less than five minutes on education, with a mean duration of 3 minutes, and only 31\% spent more than five minutes. It should be considered however, that the average time for a complete consultation was limited to 10 minutes. Moreover, the nurses declared that the time spent on oral health also depended on the specific characteristics of each family: in families with a firstborn child, or with lower-educated mothers (i.e. who did not continue educational training after primary and/or secondary school), more time was spent on oral health education. In families where other problems needed to be discussed, less time was spent on the oral health topics.

\section{Moderators}

Facilitating factors. A detailed manual, tailored training and feedback were provided to the nurses to enhance implementation fidelity. An overview of the information topics to be discussed and materials to be delivered was made on a separate sheet and included in the standard computerized record to guide the nurses during the home visits and consultations. Ninety-three percent of the nurses considered the training as sufficient in terms of content, 
extensiveness and practical applicability, and $87 \%$ found the manual easy to use. However, only $40 \%$ of the nurses reported that they actually used the manual during the contact moments. In fact, the manual was primarily used to rehearse oral health education before discussing it with the parents, to answer parents' questions, and to check if all topics had been discussed. In contrast, $87 \%$ of the nurses reported that they often or always used the comprehensive child health booklet during home visits and consultations.

Quality of delivery. The quality of the delivery, or the differences in the way the nurses implemented the intervention, could only be measured by calculating the average number of items each nurse had discussed during the contacts. According to the analyses, 15 nurses, who participated during the whole project, referred to hereafter as the "permanent" group, implemented the program most completely, as on average $70 \%$ of the parents had received all the information planned. All permanent group members were women with a mean age of 38.3 $(\mathrm{SD}=10.2)$ years and $13.8(\mathrm{SD}=11.2)$ years of professional experience in the well-baby clinic. Four nurses, who had joined the project when the intervention had already started, were also able to implement the program as planned; $63 \%$ of the parents seen by these nurses received all the oral health topics. In contrast, for the 23 nurses who participated only once or in a few consultations as replacement workers when someone of the permanent group was absent for a period of time, a lower level of implementation quality was observed. Although some of them discussed a number of topics with the parents and handed out the materials, others did not implement the program at all, probably because they were less well informed about the project and did not receive a manual or training.

Participant responsiveness. Participant responsiveness was measured via the nurses’ views as expressed during the focus interviews and in the questionnaires and via the parents' self-report questionnaires. According to the former, the parents generally showed an interest in the oral health information that was provided and supported by the comprehensive child health 
booklet, and were enthusiastic about the materials. Parents were also asked to record the emergence of every primary tooth in the booklet; these data were then copied by the nurse in the computerized record of the child. In 2004, 73\% of the parents did so, but in 2005 only 50\%. So, parents recorded the emergence of the first teeth very well, but their interest diminished with time.

Analysis of the questionnaire completed by the parents at age three (when the intervention was finished) revealed that $24 \%$ of the parents had learned 'rather more' or 'a lot' from the project. Especially the importance of starting to brush with toothpaste as soon as the first tooth had emerged was indicated as new information. Many parents (42\%) however gave a neutral reply, and 45 parents (8\%) indicated they had not learned anything. Eight parents explained that they already knew all the oral health recommendations and already displayed the recommended behavior in their daily lives. In all, 65\% of the parents responded that their attitudes towards oral health had not changed because of the program.

\section{Discussion}

The present study aimed to evaluate the fidelity with which a longitudinal intervention program to promote oral health in preschool children had been implemented using a conceptual framework of implementation fidelity (Carroll et al., 2007). The results were mixed. On the one hand, attendance at the home visits was higher than at the consultations: more than $88 \%$ of all parents received all three home visits, compared to 57\% who received at least 9 of 11 planned consultations. It must be noted that the attendance could have been higher in the contacts that were scheduled during the first three months, as mothers were still in maternity leave. Although overall the attendance level amounted to $78 \%$, which can be considered as good, the lower attendance rates at the consultations might have had an impact on the implementation fidelity. Moreover, the nurses adhered to the planning manual most of the time, as $64 \%$ of the 
intervention was delivered to the parents, $73 \%$ of the families who attended received information on all items and 52\% received all materials that were foreseen in the manual. This is in line with other implementation studies, where usually levels of around $60 \%$ are found; expecting perfect implementation is unrealistic and only a few studies have attained levels higher than $80 \%$ (Durlak \& DuPre, 2008). It was not possible to provide information on all topics to all parents, when parents were absent or needed to discuss other problems during the contacts. This problem is however inherent to the context of the well-baby clinics, which are attended on a voluntary basis. Within these contextual limits, the implementation fidelity can be considered as sufficient.

The study also looked at several moderators of implementation fidelity. While the program can be considered as complex because of the different intervention components, the potential impeding effect of this complexity on the implementation fidelity was compensated by a detailed intervention description, an appropriate use of facilitators and high participant responsiveness. Another important moderator was the quality of delivery, which was influenced through the training of the nurses. It was clear that the permanent group of nurses, who had been involved in the project during the entire intervention period and had followed the extensive training, implemented the program more completely compared to the nurses who gave only a few sessions and had received no training.

As mentioned above, the impact of the context is an important moderator. The fact that the oral health program was incorporated in an existing preventive health context had both advantages and disadvantages for the implementation fidelity (Fixsen, Naoom, Blase, Friedman, \& Wallace, 2005). On the advantage side, almost all children born in these regions could be reached without the need for a special recruitment and without setting up special visits or contact moments. The organization that implemented the intervention is well-known in Flanders and easily accessed, which means that parents from all social backgrounds attend the free preventive health visits. Implementing an additional educational program into an existing service made it 
possible to attain a high coverage of the target group. A second advantage is that it was possible to work with experienced nurses, who were used to working with parents of young children and trained to give health education. As a result, they only needed additional training in the specific topic of oral health. Third, the intervention started at birth and continued until the children reached the age of 3 years. This longitudinal approach allowed a repetition of the topics over 14 contact moments, which has shown to be effective in previous research (Scottish Intercollegiate Guidelines Network (SIGN), 2005). Fourth, oral health promotion was included in a general health promotion program, and not provided by dental health professionals. This holistic approach can add credibility. Finally, as baseline results of the Smile for Life study in 2003 indicated that $79 \%$ of the three-year-olds in these regions had never visited the dentist, it is clear that by working through the channel of the well-baby clinics, children could be reached about oral health related topics at a very young age.

On the disadvantage side, the main problem was the restricted time that was available for the nurses to spend with a family. During consultations, only 10 minutes could be devoted to delivering health information, including the extra topics on oral health, and to discuss problems in child rearing. On average, three minutes were spent to inform parents about oral health depending on the scheduled topics and on the problems parents wanted to discuss. As a result, families who wanted to discuss other, more urgent problems received less information on oral health. It is realistic to assume that these families may in fact have needed the oral health education most. Whenever possible, however, the topics that had not been discussed were transferred to the subsequent session. As there was more time available during the home visits compared to the consultations, it can be suggested that families with many problems would benefit from an extra home visit. 
Second, in case of time shortage in the well-baby clinics, the organization omitted the first or last consultations as there were no vaccinations scheduled at these contact moments. This was done beyond the control of the intervention staff and resulted in lower coverage.

Finally, it was not possible to keep the same team of nurses for the entire duration of the implementation phase. When they were absent for a period of time, they were replaced by colleagues from other regions who had not received the same training on oral health. These nurses demonstrated a much lower quality level of program delivery, which may have reduced implementation fidelity. In future interventions, a brief training or reduced manual could be distributed to these nurses. Of course, if the program would be implemented in the whole organization, this problem would not occur, as all nurses would receive the extended training.

The "Smile for Life" intervention study also had its strengths and limitations. The fact that the intervention originated from the needs identified by the nurses working in the field was its greatest strength. Involvement of the nurses in program development, thorough training and the use of a comprehensive and practical manual were all part of this program and have shown to be very important in enhancing implementation fidelity (Dane \& Schneider, 1998). Furthermore, the program was well adapted to the working context, which led to a realistic planning and feasible aims. Lastly, the intervention was developed on the basis of well-established theoretical models for health promotion and behavior change, notably the Theory of Planned Behavior (Ajzen, 1991).

On the other hand, it is also important to consider the weaknesses of the intervention study. An important weakness was that the data for the process analysis were based on registrations by the nurses who were themselves the main "actors" in the implementation of the intervention. This means that recording mistakes cannot be excluded. On the other hand the nurses were experienced in making registrations in the digital child record. During the focus interviews, the nurses admitted that they sometimes forgot to register the delivery of information 
or of educational materials. The registration data may thus be an underestimation of the real implementation. It is also likely that not only the quality of the implementation, but also the quality of the reporting was influenced by the experience, motivation and educational capacities of the nurses and by the importance they attached to oral health. This aspect, however, is very difficult to control in any process analysis. Second, implementation fidelity was measured through self-report questionnaires completed by the health care workers and parents. As selfreport data have limited validity and accuracy, the additional use of observational data would have added value (Breitenstein et al., 2010; Durlak \& DuPre, 2008). Observations of the contact moments would also facilitate the evaluation of the quality of delivery, which was currently based on quantitative data only. Observational measures of the implementation fidelity would however have been too labor-intensive and were not financially feasible.

Third, as the questionnaires for the parents were only available in Dutch, families with a different primary language - often families with an immigrant background - were not included in the program. Out of all families that did not meet the inclusion criteria, $21 \%$ were excluded because of language. Although these families were offered the same intervention (oral health education and materials) for ethical reasons, the way in which this was implemented was not recorded. In future work, outcome evaluations in these families could be performed using face to face questionnaires instead of written questionnaires. Translating the written questionnaires is another possibility. It is possible that specific actions should be developed for these groups, targeted to their needs and taking into account their cultural backgrounds. Certainly, an approach that is effective in one group may not work in another group. Tailored care may be essential. It would be interesting to investigate the impact of cultural factors on implementation (Durlak \& DuPre, 2008). Finally, the identification of the essential components of the intervention related to successful outcome was not done in this study. The relationship between implementation 
fidelity and the behavioral and oral hygiene outcome as well as the evaluation of the behavioral change techniques will be addressed in separate reports.

The results of this process analysis are of great value for understanding the limited outcomes of this study. Assessment of the implementation fidelity of complex interventions was also found to be essential to fully understand the success (or lack of success) of interventions in preventive health (Breitenstein et al., 2010; Campbell et al., 2000; Durlak \& DuPre, 2008; Oakley, Strange, Stephenson, Forrest, \& Monteiro, 2004). Although the implementation fidelity of this intervention study was generally sufficient, the study showed that it was nevertheless impeded by organizational constraints related to the context of the well-baby clinics, more specifically limited time, lower attendance on consultations and omission of consultations. It should be further investigated whether these contextual factors can explain the limited effects of the intervention.

The results of our study can contribute to the knowledge base on the conditions for successful implementation of oral health promotion programs, as process evaluations of interventions addressing oral health are seldom reported in the literature (Breitenstein et al., 2010; Dane \& Schneider, 1998). One reason for the lack of evidence about these issues is that this requires the collection of detailed information about the application of all program aspects, which is difficult to achieve in the setting of a multi-component intervention program (Hasson, 2010). Collecting implementation data should however be an essential feature of future program evaluations. Using a theoretical framework proved to be useful for assisting in a structured evaluation of the implementation process. 


\section{Acknowledgments}

The following partners collaborated in the "Smile for Life Project": Dominique Declerck (Project coordinator) and Roos Leroy (both from the Department of Oral Health Sciences, KU Leuven); Karel Hoppenbrouwers (Center of Youth Health Care, KU Leuven); Emmanuel Lesaffre (Erasmus University Rotterdam, the Netherlands); Stephan Van den Broucke (Department of Psychology, Université Catholique de Louvain); Luc Martens (Dental School, Ghent University); and Erwin Van Kerschaver and Martine Debyser (Child and Family). The study was supported financially by GABA Benelux and GABA International, a European branded manufacturer of oral care products. 


\section{References}

Ajzen, I. (1991). The theory of planned behavior. Organizational Behavior and Human Decision Processes, 50, 179-211.

Breitenstein, S. M., Gross, D., Garvey, C. A., Hill, C., Fogg, L., \& Resnick, B. (2010). Implementation fidelity in community-based interventions. Research in Nursing and Health, 33, 164-173.

Campbell, M., Fitzpatrick, R., Haines, A., Kinmonth, A. L., Sandercock, P., Spiegelhalter, D. \& Tyrer, P. (2000). Framework for design and evaluation of complex interventions to improve health. British Medical Journal, 321, 694-696.

Carroll, C., Patterson, M., Wood, S., Booth, A., Rick, J., \& Balain, S. (2007). A conceptual framework for implementation fidelity. Implementation Science, 2, 40.

Dane, A. V., \& Schneider, B. H. (1998). Program integrity in primary and early secondary prevention: are implementation effects out of control? Clinical Psychological Review, 18, 23-45.

Davies, G. M., Duxbury, J. T., Boothman, N. J., Davies, R. M., \& Blinkhorn, A. S. (2005). A staged intervention dental health promotion programme to reduce early childhood caries. Community Dental Health, 22, 118-122.

Declerck, D., Leroy, R., Martens, L., Lesaffre, E., Garcia-Zattera, M. J., Van den Broucke, S., ..., Hoppenbrouwers, K. (2008). Factors associated with prevalence and severity of caries experience in preschool children. Community Dentistry and Oral Epidemiology, 36, 168178.

Durlak, J. A., \& DuPre, E. P. (2008). Implementation matters: a review of research on the influence of implementation on program outcomes and the factors affecting implementation. American Journal of Community Psychology, 41, 327-350. 
Feldens, C. A., Vitolo, M. R., \& Drachler, M. L. (2007). A randomized trial of the effectiveness of home visits in preventing early childhood caries. Community Dentistry and Oral Epidemiology, 35, 215-223.

Fixsen, D. L., Naoom, S. F., Blase, K. A., Friedman, R. M., \& Wallace, F. (2005). Implementation research: A synthesis of the literature. Tampa, FL: University of South Florida, Louis de la Parte Florida Mental Health Institute, The National Implementation Research Network.

Green, L. W., \& Kreuter, M. W. (1999). Health Promotion Planning: An Educational and Ecological Approach ( $3^{\text {th }}$ ed.). Mayfield, Mountainview, CA.

Harris, R., Nicoll, A. D., Adair, P. M., \& Pine, C. M. (2004). Risk factors for dental caries in young children: a systematic review of the literature. Community Dental Health, 21, 7185.

Hasson, H. (2010). Systematic evaluation of implementation fidelity of complex interventions in health and social care. Implementation Science, 5, 67.

Kowash, M. B., Pinfield, A., Smith, J., \& Curzon, M. E. (2000). Effectiveness on oral health of a long-term health education programme for mothers with young children. British Dental Journal, 188, 201-205.

Leroy, R., Bogaerts, K., Martens, L., \& Declerck, D. (2011). Risk factors for caries incidence in a cohort of Flemish preschool children. Clinical Oral Investigations, 16, 805-812. doi: 10.1007/s00784-011-0579-y.

Locker, D. (2004). Oral health and quality of life. Oral Health \& Preventive Dentistry, 2 Suppl 1, 247-253.

Malterud, K. (2001). Qualitative research: standards, challenges, and guidelines. The Lancet, 358, 483-488. 
Michie, S., Johnston, M., Francis, J., Hardeman, W., \& Eccles, M. (2008). From Theory to Intervention: Mapping Theoretically Derived Behavioural Determinants to Behaviour Change Techniques. Applied Psychology: An International Review, 57, 660-680.

Mohebbi, S. Z., Virtanen, J. I., Murtomaa, H., Vahid-Golpayegani, M., \& Vehkalahti, M. M. (2008). Mothers as facilitators of oral hygiene in early childhood. International Journal of Paediatric Dentistry, 18, 48-55.

Oakley, A., Strange, V., Stephenson, J., Forrest, S., \& Monteiro, H. (2004). Evaluating Processes. Evaluation, 10, 440-462.

Plutzer, K., \& Spencer, A. J. (2008). Efficacy of an oral health promotion intervention in the prevention of early childhood caries. Community Dentistry and Oral Epidemiology, 36, 335-346.

Scottish Intercollegiate Guidelines Network (SIGN). (2005). Prevention and management of dental decay in the pre-school child. A national clinical guideline. Retrieved from http://www.sign.ac.uk/guidelines/fulltext/83/index.html.

Sheiham, A. (2006). Dental caries affects body weight, growth and quality of life in pre-school children. British Dental Journal, 201, 625-626.

Strippel, H. (2010). Effectiveness of structured comprehensive paediatric oral health education for parents of children less than two years of age in Germany. Community Dental Health, 27, 74-80.

Tinanoff, N., \& Reisine, S. (2009). Update on early childhood caries since the Surgeon General's Report. Academic Pediatrics, 9, 396-403.

Vachirarojpisan, T., Shinada, K., \& Kawaguchi, Y. (2005). The process and outcome of a programme for preventing early childhood caries in Thailand. Community Dental Health, 22, 253-259. 
Van den Branden, S., Van den Broucke, S., Leroy, R., Declerck, D., \& Hoppenbrouwers, K. (2012). Effects of time and socio-economic status on the determinants of oral healthrelated behaviours of parents of preschool children. European Journal of Oral Sciences, $120,153-160$.

Van den Branden, S., Van den Broucke, S., Leroy, R., Declerck, D., \& Hoppenbrouwers, K. (2013). Measuring determinants of oral health behaviour in parents of preschool children. Community Dental Health, 30, 19-25. 
Figure legends:

Figure 1. The modified conceptual framework for implementation fidelity (Hasson, 2010)

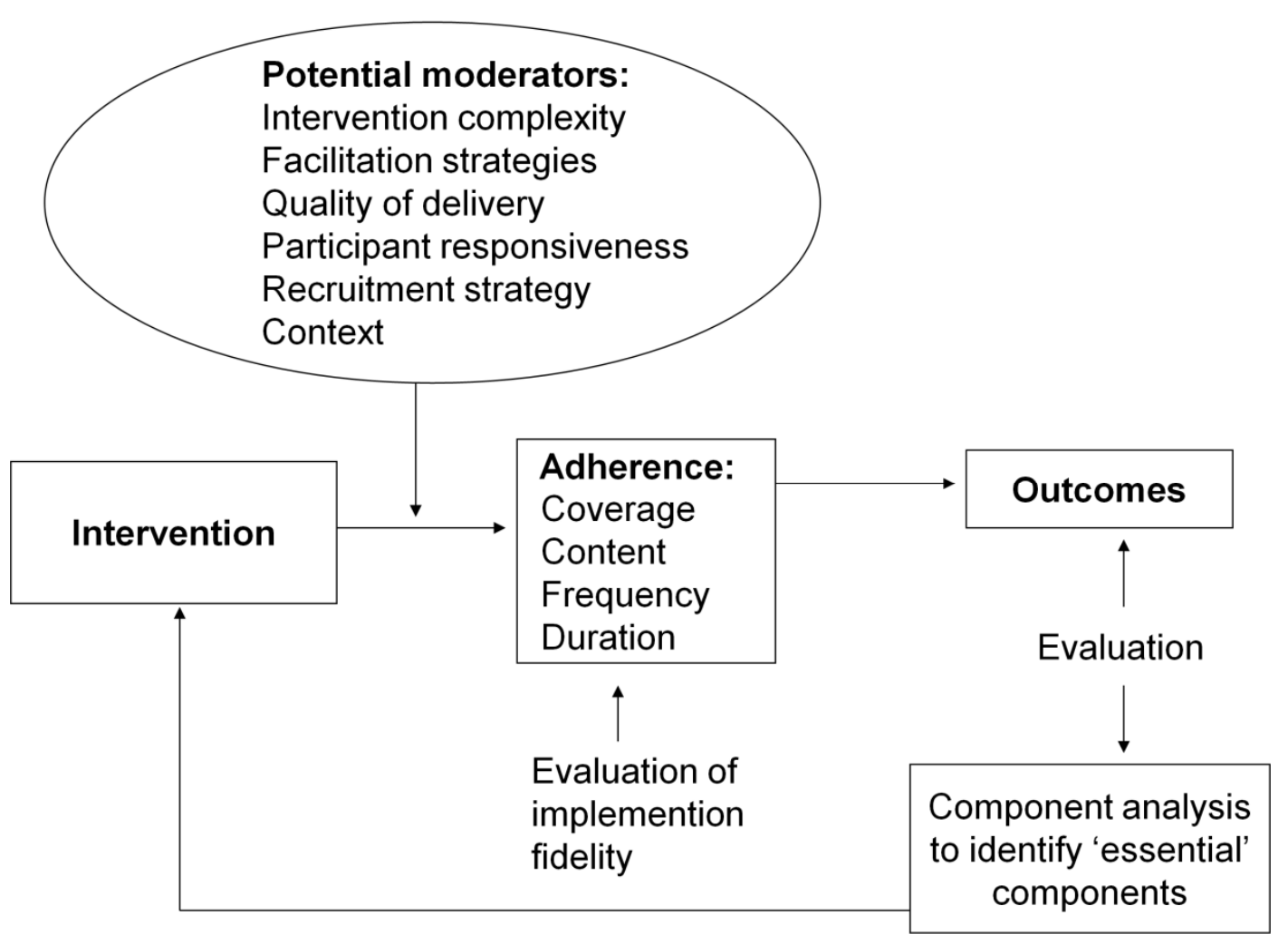


Table 1

Intervention components per contact moment

\begin{tabular}{|c|c|c|c|c|c|c|c|c|c|c|c|c|c|c|c|c|}
\hline & & $\begin{array}{l}\text { HV1 } \\
2 \mathrm{w} \\
\end{array}$ & $\begin{array}{c}\mathrm{C} 1 \\
3 / 6 \mathrm{w} \\
\end{array}$ & $\begin{array}{l}\mathrm{HV} 2 \\
4 / 6 \mathrm{w} \\
\end{array}$ & $\begin{array}{l}\text { HV3 } \\
6 / 10 w \\
\end{array}$ & $\begin{array}{l}\mathrm{C} 2 \\
8 \mathrm{w} \\
\end{array}$ & $\begin{array}{l}\text { HV4 } \\
10 \mathrm{w} \\
\end{array}$ & $\begin{array}{l}\text { C3 } \\
3 \mathrm{~m} \\
\end{array}$ & $\begin{array}{l}\mathrm{C} 4 \\
4 \mathrm{~m} \\
\end{array}$ & $\begin{array}{l}\mathrm{C} 5 \\
5 \mathrm{~m} \\
\end{array}$ & $\begin{array}{l}\mathrm{C6} 6 \\
7 \mathrm{~m} \\
\end{array}$ & $\begin{array}{c}\mathrm{C} 7 \\
10 \mathrm{~m} \\
\end{array}$ & $\begin{array}{c}\mathrm{C} 8 \\
12 \mathrm{~m} \\
\end{array}$ & $\begin{array}{c}\mathrm{C} 9 \\
15 \mathrm{~m} \\
\end{array}$ & $\begin{array}{l}\mathrm{C} 10 \\
24 \mathrm{~m} \\
\end{array}$ & $\begin{array}{l}\mathrm{C} 11 \\
30 \mathrm{~m} \\
\end{array}$ \\
\hline \multirow{13}{*}{$\begin{array}{l}\text { Oral health } \\
\text { education on }\end{array}$} & Pacifier use & $\mathrm{X}$ & $\mathrm{X}$ & & & $\mathrm{X}$ & & & & & $\mathrm{X}$ & $\mathrm{X}$ & & $\mathrm{X}$ & & \\
\hline & $\begin{array}{l}\text { Oral hygiene of the } \\
\text { parent }\end{array}$ & $\mathrm{X}$ & $\mathrm{X}$ & $\mathrm{X}$ & & $\mathrm{X}$ & & & & $\mathrm{X}$ & $\mathrm{X}$ & & & $\mathrm{X}$ & & \\
\hline & $\begin{array}{l}\text { Fluoride } \\
\text { supplements }\end{array}$ & $\mathrm{X}$ & & & & & & & & & & & & & & \\
\hline & Breathing & $\mathrm{X}$ & $\mathrm{X}$ & & & $\mathrm{X}$ & & & & & & & $X$ & & & \\
\hline & $\begin{array}{l}\text { Water and drink } \\
\text { consumption }\end{array}$ & $\mathrm{X}$ & & & $\mathrm{X}$ & & & $\mathrm{X}$ & $\mathrm{X}$ & $X$ & $\mathrm{X}$ & & $\mathrm{X}$ & & & \\
\hline & Thumb sucking & & $\mathrm{X}$ & & & $\mathrm{X}$ & & & & & & & & & & \\
\hline & Medication & & & & $\mathrm{X}$ & & & & & & & & & & & \\
\hline & $\begin{array}{l}\text { Advice about } \\
\text { nutrition }\end{array}$ & & & & & $\mathrm{X}$ & & $\mathrm{X}$ & $\mathrm{X}$ & $\mathrm{X}$ & $\mathrm{X}$ & $\mathrm{X}$ & $\mathrm{X}$ & $\mathrm{X}$ & $\mathrm{X}$ & $\mathrm{X}$ \\
\hline & Dental trauma & & & & & & & & & & & & $\mathrm{X}$ & & $\mathrm{X}$ & \\
\hline & Nurturing & & & & & & & $\mathrm{X}$ & & & & & & $\mathrm{X}$ & $\mathrm{X}$ & \\
\hline & Tooth emergence & & & & & & & & & $\mathrm{X}$ & $\mathrm{X}$ & $\mathrm{X}$ & & & & \\
\hline & $\begin{array}{l}\text { Oral hygiene of the } \\
\text { child }\end{array}$ & & & & & & & & & & $\mathrm{X}$ & $\mathrm{X}$ & $X$ & $\mathrm{X}$ & $\mathrm{X}$ & $\mathrm{X}$ \\
\hline & Visit to the dentist & & & & & & & & & & & & & & $\mathrm{X}$ & $\mathrm{X}$ \\
\hline \multirow{4}{*}{$\begin{array}{l}\text { Educational } \\
\text { materials }\end{array}$} & Health booklet & $\mathrm{X}$ & & & & & & & & & & & & & & \\
\hline & Toothbrush and cup & & & & & & & & & & $\mathrm{X}$ & & & & & \\
\hline & Placemat & & & & & & & & & & & & $\mathrm{X}$ & & & \\
\hline & $\begin{array}{l}\text { Toothbrush and - } \\
\text { paste }\end{array}$ & & & & & & & & & & & & & & $\mathrm{X}$ & \\
\hline
\end{tabular}

Note: $\mathrm{HV}=$ Home visit, $\mathrm{C}=$ Consultation, w: weeks, m: months 
Table 2

Behavioral change techniques, applied methods and materials and measurements of implementation fidelity for every determinant

\begin{tabular}{|c|c|c|c|}
\hline $\begin{array}{l}\text { Determinant } \\
\text { of behavior }\end{array}$ & Behavioral change technique & Methods and materials & $\begin{array}{l}\text { Measurement of } \\
\text { implementation } \\
\text { fidelity }\end{array}$ \\
\hline $\begin{array}{l}\text { Knowledge } \\
\text { Attitudes } \\
\text { (TPB) }\end{array}$ & $\begin{array}{ll}\text { - } & \text { Information regarding } \\
& \text { behavior / outcome } \\
\text { - } & \text { Persuasive communication } \\
\text { - } & \text { Feedback }\end{array}$ & $\begin{array}{ll}\text { - } & \text { Oral communication } \\
& \text { with parents } \\
\text { - } & \text { Health booklet / } \\
& \text { Pamphlet / Poster }\end{array}$ & $\begin{array}{l}\text { Coverage } \\
\text { Content } \\
\text { Frequency } \\
\text { Duration }\end{array}$ \\
\hline $\begin{array}{l}\text { Social norms } \\
\text { and influences } \\
\text { (TPB) }\end{array}$ & $\begin{array}{ll}\text { - } & \text { Involvement of community } \\
\text { health workers and child care } & \text { centers } \\
\text { - } & \text { Social processes of } \\
\text { encouragement and support }\end{array}$ & $\begin{array}{l}\text { - Information session } \\
\text { for health workers in } \\
\text { community } \\
\text { - Training for program } \\
\text { implementers }\end{array}$ & $\begin{array}{l}\text { Number of } \\
\text { referrals/advices } \\
\text { Evaluation of } \\
\text { training/information } \\
\text { sessions/project }\end{array}$ \\
\hline $\begin{array}{l}\text { Perceived } \\
\text { behavioral } \\
\text { control (TPB) }\end{array}$ & $\begin{array}{ll}\text { - } & \text { Environmental changes (e.g. } \\
\text { distribution of objects to } \\
\text { facilitate behavior) } \\
\text { - } & \text { Social processes of } \\
\text { encouragement and support } \\
\text { - } & \text { Feedback }\end{array}$ & $\begin{array}{ll}\text { - } & \text { Oral communication } \\
\text { with parents } \\
\text { - } \\
\text { Distribution of } \\
\text { toothbrush, toothpaste } \\
\text { and cup twice }\end{array}$ & $\begin{array}{l}\text { Coverage } \\
\text { Content } \\
\text { Frequency } \\
\text { Duration }\end{array}$ \\
\hline $\begin{array}{l}\text { Intention } \\
\text { (TPB) }\end{array}$ & $\begin{array}{ll}\text { - } & \text { Information regarding } \\
\text { behavior / outcome } \\
\text { - } & \text { Goal / target specified: } \\
\text { behavior or outcome } \\
\text { - } & \text { Social processes of } \\
\text { encouragement and support } \\
\text { - } & \text { Persuasive communication }\end{array}$ & $\begin{array}{ll}\text { - } & \text { Oral communication } \\
\text { with parents } \\
\text { - } & \text { Health booklet }\end{array}$ & $\begin{array}{l}\text { Coverage } \\
\text { Content } \\
\text { Frequency } \\
\text { Duration }\end{array}$ \\
\hline $\begin{array}{l}\text { Memory, } \\
\text { attention, } \\
\text { decision } \\
\text { processes }\end{array}$ & - Prompts, triggers, cues & 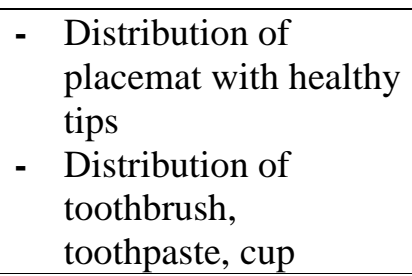 & $\begin{array}{l}\text { Coverage } \\
\text { Content } \\
\text { Frequency } \\
\text { Duration }\end{array}$ \\
\hline
\end{tabular}

Note: TPB: Theory of Planned Behavior 


\section{EVALUATION OF IMPLEMENTATION FIDELITY}

Table 3

Attendance and intervention dose on every contact moment

\begin{tabular}{lcccccccccccccc}
\hline & HV1 & HV2 & HV3 & C1 & C2 & C3 & C4 & C5 & C6 & C7 & C8 & C9 & C10 & C11 \\
\hline Attendance, N & 1044 & 1036 & 936 & 349 & 939 & 942 & 861 & 901 & 898 & 820 & 892 & 882 & 669 & 552 \\
\multicolumn{1}{c}{ \% } & 96.7 & 95.9 & 86.7 & 32.3 & 86.9 & 87.2 & 79.7 & 83.4 & 83.1 & 75.9 & 82.6 & 81.7 & 61.9 & 51.1 \\
Intervention components delivered, mean & 5.1 & 0.7 & 1.4 & 1.1 & 2.9 & 2.2 & 1.3 & 2.9 & 5.2 & 2.6 & 5.0 & 3.5 & 3.9 & 1.2 \\
SD & 1.9 & 0.4 & 0.9 & 1.8 & 2.4 & 1.3 & 1.0 & 1.9 & 2.6 & 1.9 & 2.9 & 2.2 & 2.4 & 1.2 \\
Maximum of intervention components planned, N & 6 & 1 & 2 & 4 & 5 & 3 & 2 & 5 & 7 & 4 & 6 & 5 & 6 & 3 \\
Dose (\%) & 85.0 & 74.0 & 68.5 & 27.0 & 58.4 & 72.7 & 63.5 & 57.0 & 74.3 & 64.5 & 83.3 & 69.0 & 65.0 & 38.3 \\
\hline
\end{tabular}

Note: $\mathrm{HV}=$ Home Visit, $\mathrm{C}$ = Consultation, $\mathrm{SD}=$ Standard deviation 